\title{
A novel splice variant of the stem cell marker LGR5/GPR49 is correlated with the risk of tumor- related death in soft-tissue sarcoma patients
}

\author{
Swetlana Rot ${ }^{1 \dagger}$, Helge Taubert ${ }^{2,4,5}$, Matthias Bache ${ }^{1}$, Thomas Greither ${ }^{3}$, Peter Würl ${ }^{6}$, Alexander W Eckert ${ }^{2}$,
} Johannes Schubert ${ }^{2}$, Dirk Vordermark ${ }^{1 \dagger}$ and Matthias Kappler ${ }^{2^{*+}}$

\begin{abstract}
Background: The human leucine-rich, repeat-containing G protein-coupled receptor (LGR) 5, also called GPR49, is a marker of stem cells in adult intestinal epithelium, stomach and hair follicles. LGR5/GPR49 is overexpressed in tumors of the colon, ovary and liver and in basal cell carcinomas. Moreover, an expression in skeletal muscle tissues was also detected. However, there has been no investigation regarding the expression and function of LGR5/GPR49 in soft-tissue sarcomas (STS) yet.

Methods: Seventy-seven frozen tumor samples from adult STS patients were studied using quantitative real-time TaqManTM PCR analysis. The mRNA levels of wild type LGR5/GPR49 and a newly identified splice variant of LGR5/ GPR49 lacking exon 5 (that we called GPR49 45 ) were quantified.

Results: A low mRNA expression level of GPR49 4 , but not wild type LGR5/GPR49, was significantly correlated with a poor prognosis for the disease-associated survival of STS patients ( $R R=2.6 ; \mathrm{P}=0.026$; multivariate Cox's regression hazard analysis). Furthermore, a low mRNA expression level of GPR49 $\triangle 5$ was associated with a shorter recurrence-free survival $(P=0.043)$. However, tumor onset in patients with a lower expression level of GPR49 $\triangle 5$ mRNA occurred 7.5 years later $(P=0.04)$ than in patients with a higher tumor level of GPR49 $\triangle 5$ mRNA.

Conclusion: An attenuated mRNA level of the newly identified transcript variant GPR49 $\triangle 5$ is a negative prognostic marker for disease-associated and recurrence-free survival in STS patients. Additionally, a lower GPR49A5 mRNA level is associated with a later age of tumor onset. A putative role of GPR49 $\triangle 5$ expression in tumorigenesis and tumor progression of soft tissue sarcomas is suggested.
\end{abstract}

\section{Background}

Treatment options for soft tissue sarcomas (STS) are often limited to surgery with the possibility of adjuvant chemotherapy and radiotherapy. The 5-year survival rate for STS patients is approximately $50 \%$ and depends strongly on the tumor stage [1]. Therefore, it is necessary to develop new prognostic markers with the potential to estimate the efficacy of an individual therapeutic strategy.

STS are a heterogeneous group of relatively aggressive tumors probably originating from adult mesenchymal

\footnotetext{
* Correspondence: matthias.kappler@medizin.uni-halle.de

+ Contributed equally

${ }^{2}$ Department of Oral and Maxillofacial Plastic Surgery, Martin-Luther-

University Halle-Wittenberg, Halle(S), Germany

Full list of author information is available at the end of the article
}

stem cells (hMSCs) [2-4]. A study regarding a subgroup of STS (malignant fibrous histiocytoma; MFH) described hMSCs as the progenitors of MFH. Furthermore, the authors reported a novel tumor suppression role for Wnt signaling in solid tumors, which may have the potential for a new therapeutic strategy in sarcomas [5].

Here, we investigated the prognostic impact of the stem cell marker, cancer-associated gene and Wnt/Tcf4 target gene LGR5/GPR49 [6] in STS for the first time.

The leucine-rich repeat-containing $G$ protein-coupled receptor LGR5/GPR49 has been identified as a novel stem cell marker in intestinal epithelia, stomach, and hair follicles [7-9]. Furthermore, LGR5/GPR49 mRNA was found to be expressed in normal human skeletal

\section{C) Biomed Central}

(C) 2011 Rot et al; licensee BioMed Central Ltd. This is an Open Access article distributed under the terms of the Creative Commons Attribution License (http://creativecommons.org/licenses/by/2.0), which permits unrestricted use, distribution, and reproduction in any medium, provided the original work is properly cited. 
muscle tissues, which is of mesenchymal origin like STS [10].

LGR5/GPR49 mRNA is expressed in basal cell carcinoma (tumor of hair follicle), colorectal cancer and in tumors of the colon, ovary and liver [10-13]. Investigations of the LGR5/GPR49 protein expression are rare $[14,15]$ because a full accepted antibody against LGR5/ GPR49 is not available at the moment $[6,16]$. However, a prognostic impact of $L G R 5 / G P R 49$ has not been shown so far.

The function of LGR5/GPR49 in tumorigenesis is supported by its ability to induce transformation of NIH3T3 cells in the presence of conditioned media from colorectal tumor cells. These findings indicate the possibility that the ligand of $L G R 5 / G P R 49$ could be secreted by tumor cells [10]. McClanahan and colleagues therefore suggest a role for $L G R 5 / G P R 49$ as a member of a novel class of transforming oncogenes and, as a result, a new potential molecular target for therapeutic intervention [10].

To our knowledge only one transcript variant of LGR5/GPR49, which lacks exon 8, is published in the ExPASy UniProtKB-data bank as variant VSP_037746 http://www.uniprot.org/uniprot/O75473. In this study, we identified a novel transcript variant of LGR5/GPR49 that lacks exon 5 (GPR49 5 ) (listed by us in the EMBLBank; http://www.ebi.ac.uk/ena/data/view/FN820440).

These variants are very interesting because both published LGR5/GPR49 variants have a truncated ligand binding extracellular domain $[6,10]$. It is possible that the affinity of these variants to the recently identified ligand of the full length LGR5/GPR49 gene product [17] is different or that different ligands could bind to the shortened receptor.

In summary, we report the first results for a newly identified variant of the LGR5/GPR49 gene, lacking exon 5, that we call GPR49A5. This is the first study that has demonstrated a prognostic impact of a LGR5/GPR49 variant in STS. In a multivariate Cox's regression analysis, we found that a low GPR49 55 mRNA level is an independent negative prognostic marker for diseaseassociated survival as well as for recurrence-free survival in STS patients.

\section{Methods}

\section{Tissue samples and histopathological data}

We examined frozen tumor samples from 77 STS patients using a real-time quantitative $\operatorname{TaqMan}^{\mathrm{TM}}$ analysis. The patients' median age was 59 years (ranging from 22 to 87 years). Forty-one patients (53\%) died from their tumor after an average time of 28 months (ranging from 2-119 months), and 36 patients (47\%) were still alive after an average observation period (i.e. after primary tumor resection) of 65 months (ranging from 11-146 months). The histopathological and clinical data has been summarized in Table 1 as described previously [18]. All tumor samples were collected before radio- or chemotherapy. After the tumor operation 27/77 patients were treated only with radiotherapy, two out of 77 patients were treated only with chemotherapy, and four patients were treated with a combination of chemotherapy and radiotherapy.

The study was carried out in compliance with the Helsinki Declaration, and it was approved by the Ethics Committee of the Medical Faculty of the University Halle. All patients gave written informed consent (Department of Surgery 1, University of Leipzig, Germany).

\section{Quantitative RT-PCR}

Isolation of total RNA and cDNA synthesis were performed according to standard protocols as described previously [19]. The cDNA was amplified by automated real-time quantitative TaqMan ${ }^{\mathrm{TM}}$ assays for the wild type LGR5/GPR49 and GPR $49 \Delta 5$ transcript variants and Hypoxanthin- guanine -phosphoribosyltransferase (HPRT) transcript using kits from Roboscreen (AJRoboscreen $\mathrm{GmbH}$, Leipzig, Germany).

Wild type LGR5/GPR49 and GPR49D5 transcript amounts were correlated to HPRT transcript amounts as zeptomole (zmol, $10^{-21}$ ) wild type LGR5/GPR49 or GPR49 5 mRNAs per molecule HPRT mRNA in duplicate measurements.

An elevated expression of wild type LGR5/GPR49 was determined as an expression of $>1.07 \times 10^{-5} \mathrm{zmol}$ wild type $L G R 5 / G P R 49 \mathrm{mRNA} / \mathrm{molecule} H P R T \mathrm{mRNA}$ and for GPR49 45 as an expression of $>7.6 \times 10^{-6} \mathrm{zmol}$ GPR49 5 mRNA/molecule HPRT mRNA.

\section{Statistical analysis}

Cox's regression hazard models and Kaplan-Meier analyses were used to estimate a correlation of wild type LGR5/GPR49 and GPR49 5 mRNA with disease-associated survival of STS patients. Cox's regression hazard model was adjusted to the prognostic effect of covariates (gender of patients, tumor stage, tumor entity, tumor localization, and type of tumor resection), and the relative risk (RR) was calculated. For analyzing the recurrence-free survival of STS patients, a KaplanMeier analysis was performed. The follow-up time starts with the day of primary tumor operation. The end point for the disease-associated survival analysis was the time of death of the patient. The end point for the recurrence-free survival analysis was the first recurrence. The interrelationship between gene expression levels was tested with the Spearman's rank correlation ( $r$, correlation coefficient). A probability $(\mathrm{P})$ of $<$ 0.05 was defined as significant. Statistical analyses were 
Table 1 Histopathological and clinical data

\begin{tabular}{|c|c|c|c|c|c|}
\hline \multirow[t]{2}{*}{ Category } & \multirow[t]{2}{*}{ Patients } & \multicolumn{2}{|c|}{$\begin{array}{c}\text { GPR49-mRNA level } \\
\text { in zmol/molecule HPRT }\end{array}$} & \multicolumn{2}{|c|}{ GPR49 5-mRNA level in zmol/molecule HPRT } \\
\hline & & $\leq 1.07 * 10^{-5}$ & $>1.07^{*} 10^{-5}$ & $\leq 7.6^{*} 10^{-6}$ & $>7.6^{*} 10^{-6}$ \\
\hline \multirow[t]{2}{*}{ Total } & 77 & 39 & 38 & 39 & 38 \\
\hline & & \multicolumn{2}{|c|}{$P=0.429$} & \multicolumn{2}{|c|}{$P=0.212$} \\
\hline Men & 35 & 16 & 19 & 15 & 20 \\
\hline Women & 42 & 23 & 19 & 24 & 18 \\
\hline Tumor stage & & \multicolumn{2}{|c|}{$P=0.023^{*}$} & \multicolumn{2}{|c|}{$P=0.005^{*}$} \\
\hline 1 & 10 & 1 & 9 & 0 & 10 \\
\hline$\|$ & 33 & 21 & 12 & 21 & 12 \\
\hline III & 26 & 12 & 14 & 13 & 13 \\
\hline IV & 8 & 5 & 3 & 5 & 3 \\
\hline Tumor type & & \multicolumn{2}{|c|}{$P=0.194$} & \multicolumn{2}{|c|}{$P=0.166$} \\
\hline liposarcoma & 19 & 6 & 13 & 5 & 14 \\
\hline fibrosarcoma/malignant fibrous histiocytoma & 20 & 9 & 11 & 11 & 9 \\
\hline neurogenic sarcoma & 6 & 3 & 3 & 3 & 3 \\
\hline rhabdomyosarcoma/leiomyosarcoma & 22 & 15 & 7 & 14 & 8 \\
\hline Other STS & 10 & 6 & 4 & 6 & 4 \\
\hline Tumor resection & & \multicolumn{2}{|c|}{$P=0.377$} & \multicolumn{2}{|c|}{$P=0.172$} \\
\hline radical (R0) & 51 & 24 & 27 & 23 & 28 \\
\hline not radical (R1) & 26 & 15 & 11 & 16 & 10 \\
\hline \multicolumn{6}{|l|}{ Patients at follow-up } \\
\hline alive & 36 & 15 & 21 & 13 & 23 \\
\hline dead & 41 & 24 & 17 & 26 & 15 \\
\hline Localization & & \multicolumn{2}{|c|}{$P=0.444$} & \multicolumn{2}{|c|}{$P=0.207$} \\
\hline extremities & 49 & 25 & 24 & 26 & 23 \\
\hline thorax & 6 & 2 & 4 & 1 & 5 \\
\hline head & 1 & 0 & 1 & 0 & 1 \\
\hline abdomen & 19 & 10 & 9 & 10 & 9 \\
\hline multiple & 2 & 2 & 0 & 2 & 0 \\
\hline Metastasis & & \multicolumn{2}{|c|}{$P=0.291$} & \multicolumn{2}{|c|}{$P=0.025^{*}$} \\
\hline MO & 21 & 9 & 12 & 7 & 14 \\
\hline M1 & 29 & 17 & 12 & 19 & 10 \\
\hline Age of tumor onset & & \multicolumn{2}{|c|}{$P=0.218$} & \multicolumn{2}{|c|}{$P=0.039^{*}$} \\
\hline age (mean) & & 59.9 & 55.4 & 61.4 & 53.9 \\
\hline Kaplan-Meier analysis & & \multicolumn{2}{|c|}{$P=0.056$} & \multicolumn{2}{|c|}{$P=0.004^{*}$} \\
\hline mean survival (months) & & $50.1 \pm 6.5$ & $80.3 \pm 10.7$ & $45.8 \pm 6.4$ & $86.2 \pm 10.9$ \\
\hline Univariate Cox's Regression & & \multicolumn{2}{|c|}{$P=0.06$} & \multicolumn{2}{|c|}{$P=0.006^{*}$} \\
\hline RR & & \multicolumn{2}{|c|}{1.8} & & \\
\hline $\mathrm{Cl}$ & & & & & \\
\hline Multiv. Cox's-Regression & & & .12 & & \\
\hline RR & & & & & \\
\hline $\mathrm{Cl}$ & & & & & \\
\hline
\end{tabular}

carried out using SPSS software version 17.0 (SPSS Inc., Chicago, USA).

\section{Results}

Correlation of the mRNA expression level with survival of the STS patients

The median transcript ratios of 77 STS samples were $1.07 \times 10^{-5}$ (ranging from $0-4.1 \times 10^{-3}$; mean $2.3 \times 10^{-4}$ ) zmol wild type LGR5/GPR49 mRNA and $7.6 \times 10^{-6}$ (ranging from 0-6.4 $\times 10^{-3}$; mean $2.5 \times 10^{-4}$ ) zmol GPR49 5 mRNA/molecule HPRT mRNA, respectively.

For the survival analysis, STS patients' data were separated according to the median expression levels. GPR49 low expression was defined as $\leq 1.07 * 10^{-5}$ GPR49 mRNA/molecule HPRT mRNA (39 patients) and high expression was defined as $>1.07^{*} 10^{-5}$ GPR49 mRNA/ 
molecule HPRT (38 patients). For GPR49 45 , low expression was defined as $\leq 7.6^{*} 10^{-6}$ GPR $49 \Delta 5$ mRNA/ molecule HPRT mRNA (39 patients and high expression was defined as $>7.6 * 10^{-6}$ GPR $49 \Delta 5 \mathrm{mRNA} /$ molecule HPRT) (38 patients). The separation was based on the median expression level of the wild type LGR5/GPR49 mRNA and GPR49 55 mRNA (see also Table 1).

We performed a Kaplan-Meier analysis, which detected that STS patients with a lower intratumoral expression of wild type LGR5/GPR49 mRNA died an average of 30 months earlier $(\mathrm{P}=0.056)$, with lower intratumoral GPR49 5 mRNA expression died an average of 40 months earlier $(\mathrm{P}=0.004)$ than patients who had higher intratumoral expression of wild type LGR5/GPR49 mRNA and GPR49 5 mRNA, respectively (Table 1). Multivariate Cox's regression hazard analysis revealed an increased risk $(\mathrm{RR}=1.8, \mathrm{P}=0.12$, Table 1$)$ of tumorrelated death for patients with a low wild type LGR5/ GPR49 mRNA level and a 2.6-fold $(P=0.026)$ increased risk for STS patients with a low level of GPR49 5 mRNA in their tumors, respectively (Figure 1).

Moreover, when we estimated recurrence-free survival, a low level of GPR49 5 mRNA expression was significantly associated with an early recurrence $(P=0.043$;
Figure 2), whereas low wild type $L G R 5 / G P R 49$ mRNA expression levels had no significant effect $(P=0.20)$.

Furthermore, we found a significant difference in tumor onset (7.5 yrs) between STS patients with a low level compared to patients with a high level of GPR49 45 mRNA expression (61.4 vs. 53.9 yrs) in their tumors ( $P$ $=0.039$; Student's t-test, Table 1; Figure 3).

\section{Correlation with clinical parameters}

Bivariate analysis demonstrated that low expression of wild type $L G R 5 / G P R 49$ mRNA correlated with higher tumor stage $(P=0.02)$. Low expression of GPR49 45 mRNA was also significantly associated with higher tumor stage $(\mathrm{P}=0.005)$ and, moreover, with the occurrence of late distant metastases $(\mathrm{P}=0.025)$ (Table 1$)$. The mean intratumoral expression of GPR $49 \Delta 5$ mRNA in the primary tumor was a 6 fold lesser $\left(6.9 \times 10^{-5}\right.$ vs. 4.3 $\times 10^{-4} \mathrm{zmol}$ GPR49 $55 \mathrm{mRNA} /$ molecule HPRT mRNA) for those patients $(n=29)$ who developed metastases compared to patients $(n=21)$ without metastases.

\section{Discussion}

In this study, we demonstrated that a low GPR49 5 mRNA level is a negative prognostic marker for disease-

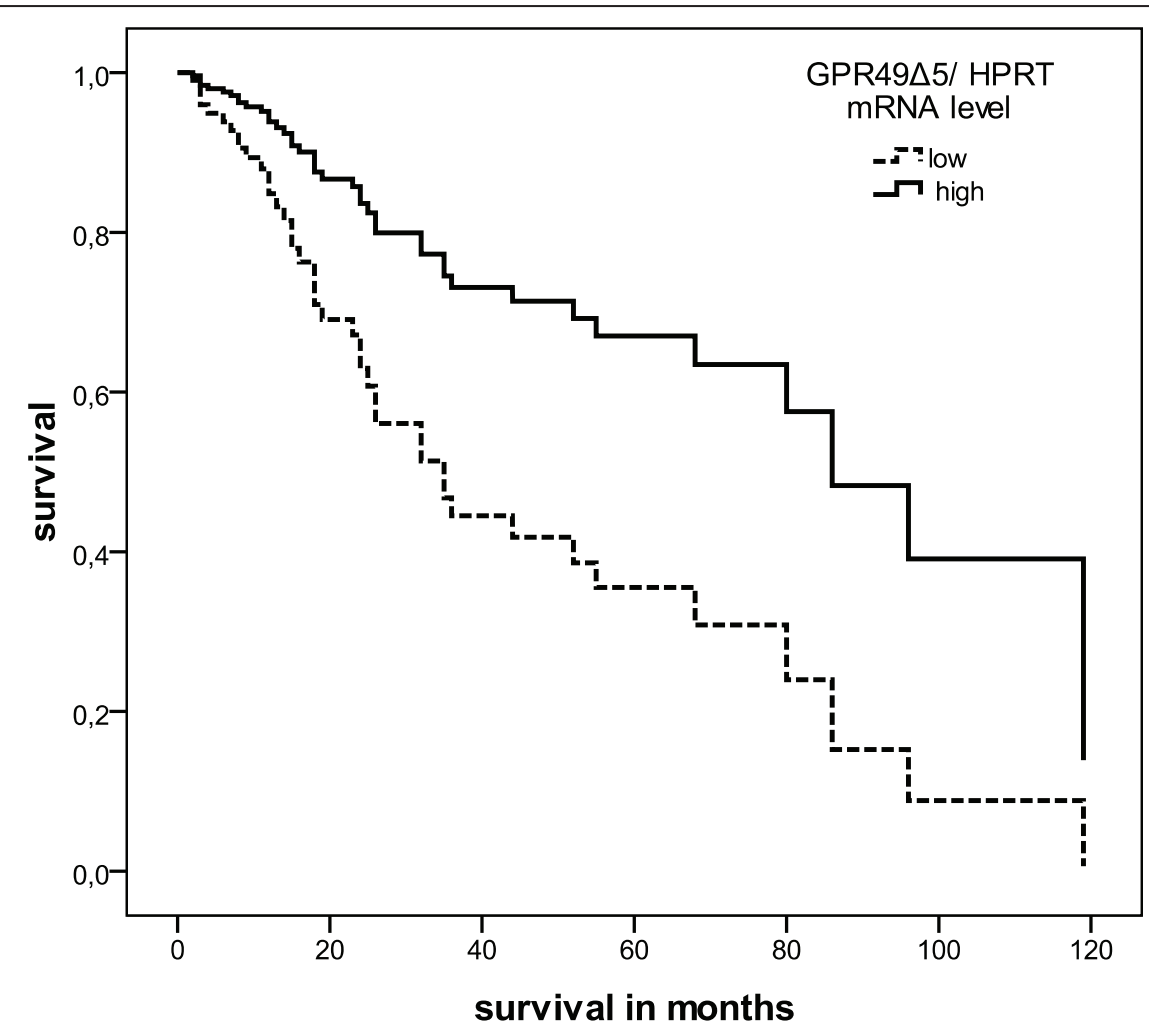

Figure 1 Multivariate Cox's hazard regression model for GPR49 $\triangle 5$ mRNA expression level and disease-associated survival in STS patients. Expression level of GPR49 $\triangle 5$ mRNA in STS of 77 patients was correlated with disease-associated survival. The model was adjusted to patients' gender, tumor stage, tumor localization, tumor entity, and the type of tumor resection. The high and low cut-off values for GPR49A5 were $>7.6 \times 10^{-5}$ and $\leq 7.6 \times 10^{-5} \mathrm{zmol}$ GPR49 $\triangle 5 \mathrm{mRNA}$ /molecule HPRT $\mathrm{mRNA}(\mathrm{RR}=2.6, \mathrm{P}=0.026)$. 


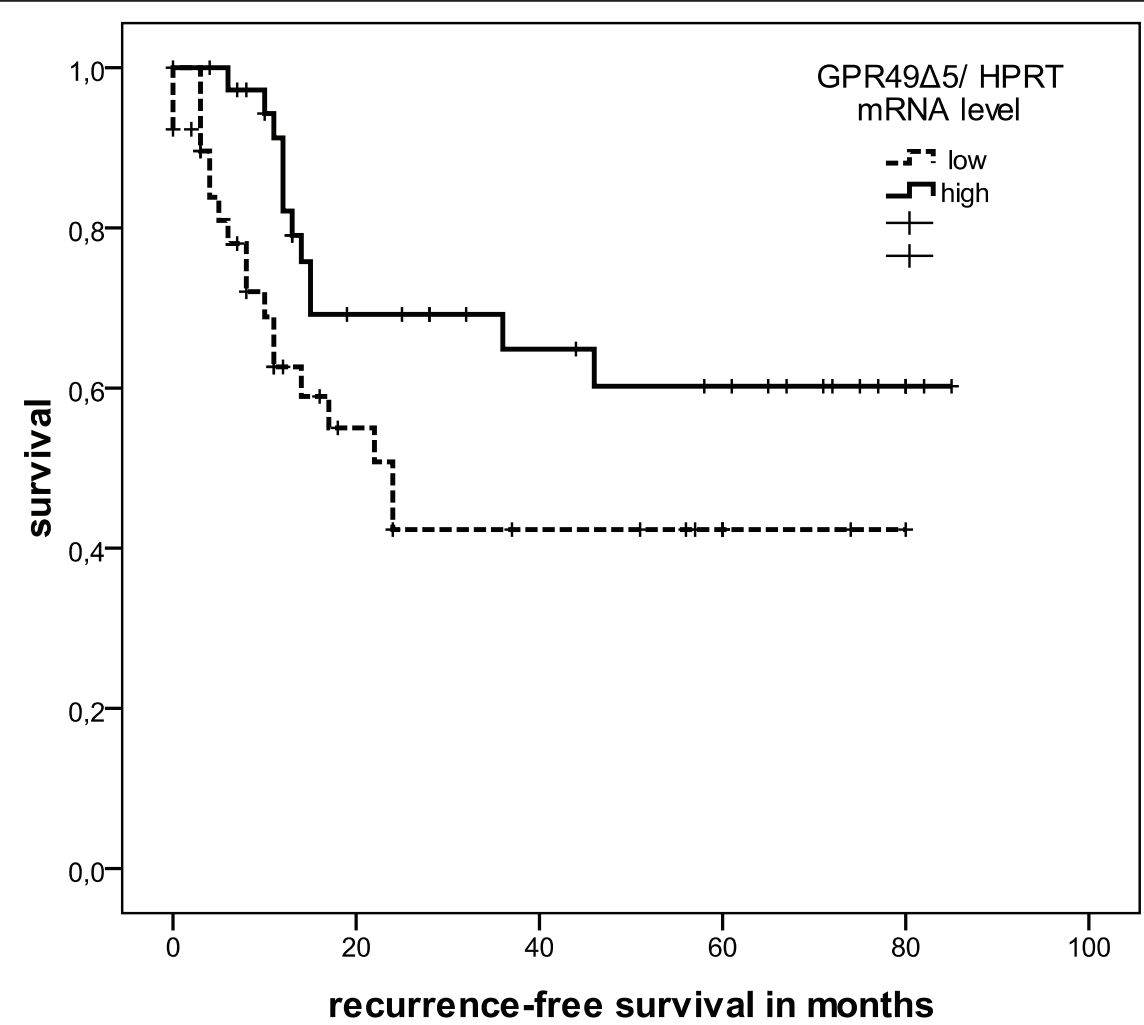

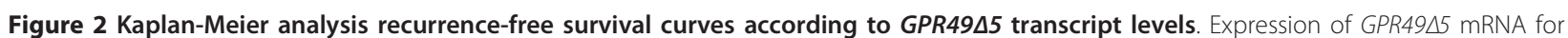
77 patients with STS was correlated with recurrence-free survival. The high and low cut-off values for GPR49 $\Delta 5$ were $>7.6 \times 10^{-5}$ and $\leq 7.6 \times 10^{-5}$ zmol GPR49 5 mRNA/molecule HPRT mRNA $(P=0.043)$.

associated and recurrence-free survival in STS patients (Table 1).

LGR5/GPR49 labels stem cells in intestines, stomach and hair follicles [7-9]. When compared to corresponding normal tissues, LGR5/GPR49 mRNA is overexpressed in human hepatocellular carcinomas, basal cell carcinoma, colon-, colorectal- and ovarian tumors [10-13,20]. However, Yamamoto et al. found no significant association between expression of LGR5/GPR49 and clinicopathologic features of tumors [12]. We found that low mRNA expression of GPR49 5 has a prognostic impact for STS patients.

Why does low expression impact survival? We found that low expression of wild type LGR5/GPR49 mRNA (P $=0.023)$, as well as low expression of GPR49 5 mRNA $(P=0.005)$, was significantly associated with a higher tumor stage. STS patients with high-stage tumors have a poorer prognosis than those with low-stage tumors [21]. In accordance with our results, McClanahan and colleagues observed that in both colorectal and ovarian carcinomas expression of $L G R 5 / G P R 49$ mRNA was high in stage I and II tumors and appears to decrease in stage III and IV tumors. The authors suggest that overexpression of $L G R 5 / G P R 49$ may be an early event in tumorigenesis
[10]. Furthermore, using a mouse endometrial cancer model, Sun et al. found that LGR5/GPR 49 mRNA is highly expressed in the epithelium during the initial stages of tumorigenesis, but is remarkably down-regulated in full-grown tumors [22]. Fan et al. postulated a function for LGR5/GPR49 in the initiation of colorectal carcinomas [14]. This hypothesis corresponds with our finding that patients with lower-staged tumors had higher GPR49 55 mRNA levels, but earlier tumor onset.

However, low expression of GPR49 5 mRNA appears to be associated with tumor progression. Low expression of GPR49 5 mRNA is correlated with poor recurrencefree survival $(P=0.043)$ in STS patients and with the occurrence of late distant metastases $(P=0.025)$. Uchida et al. described diffuse LGR5/GPR49 mRNA expression in the entire tumor, as well as in the invasive front of human colorectal carcinomas [20]. LGR5/GPR49 mRNA expression in colorectal carcinomas correlated significantly with the number of lymph node metastases, lymphatic invasion, and vascular invasion [20]. Moreover, the expression of LGR5/GPR49 mRNA was significantly associated with poor prognosis for disease-free survival of colorectal cancer patients [11]. These data suggest, that LGR5/GPR49 mRNA expression may be associated 


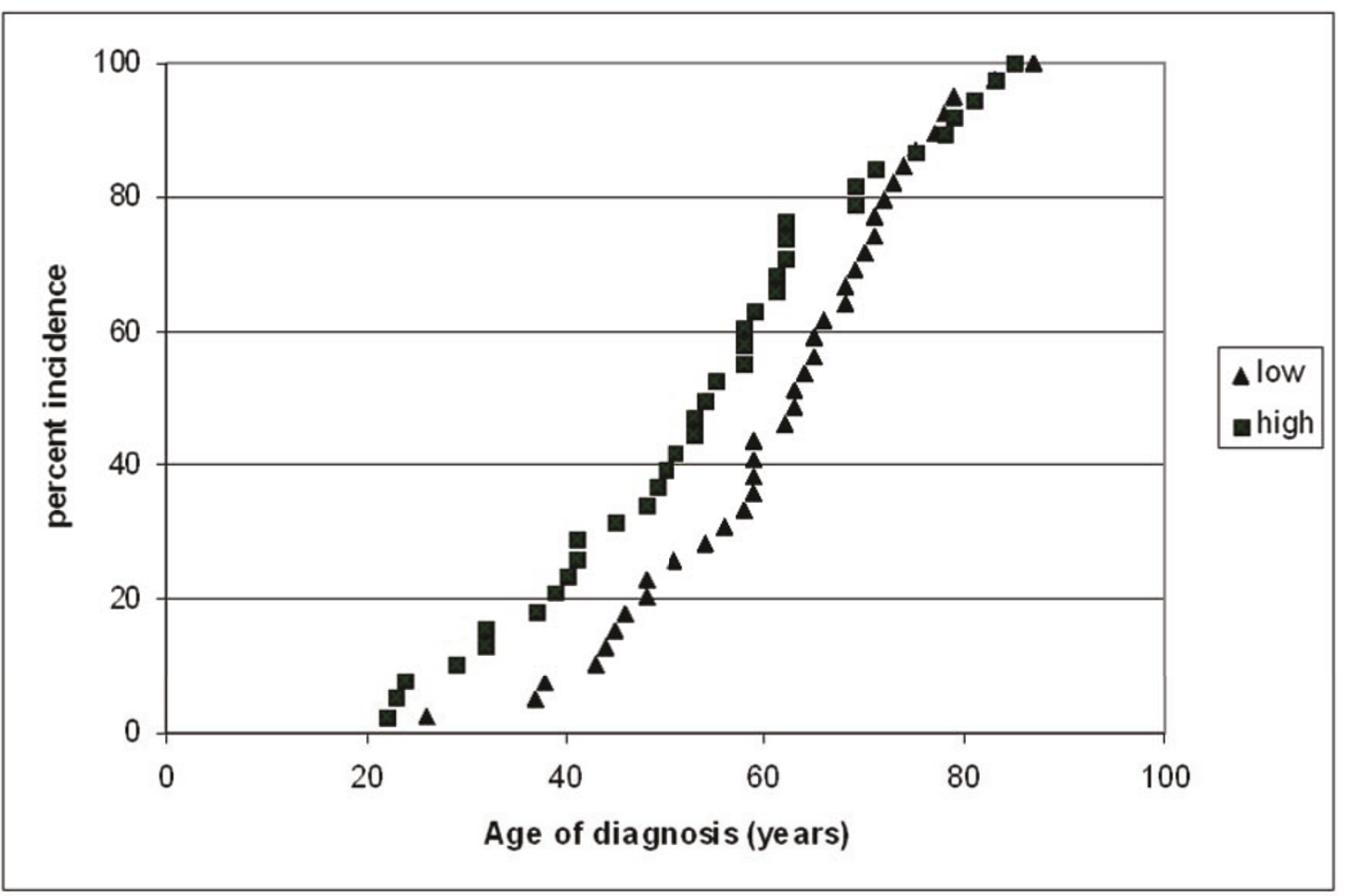

Figure 3 Correlation of GPR49 5 mRNA expression with age of tumor onset. There is a significant difference in the onset of the tumor (7.5 yrs) between STS patients with a low level $\left(>7.6 \times 10^{-5} \mathrm{zmol}\right.$ GPR49 $\triangle 5 \mathrm{mRNA}$ /molecule HPRT mRNA) (61.4 yrs) compared to patients with a high level $\left(\leq 7.6 \times 10^{-5} \mathrm{zmol}\right.$ GPR49 $\triangle 5 \mathrm{mRNA}$ /molecule HPRT mRNA) of GPR49 45 tumor mRNA expression (53.9 yrs) $(\mathrm{P}=0.039)$.

with the malignant potential of colorectal cancer, including the appearance of metastasis [20].

Recently and in accordance to our results, Walker and colleagues described that an ablation of LGR5 induces increased invasion and anchorage-independent growth, and enhances tumourigenicity in xenografts experiments of human colorectal cancers. Suppression of LGR5/ GPR49 leads to a strong upregulation of mesenchymal genes and of genes positively regulating EMT (Epithelial to Mesenchymal Transition) - the same genes are markedly downregulated upon LGR5 overexpression [23]. These findings suggest that LGR5/GPR49 is important in restricting stem cells to their niche, and that loss of LGR5 concomitant with activated wnt signalling may contribute to the invasive phenotype of colorectal carcinomas. These results highlight the importance of LGR5, not simply as marker of colorectal tumor cells, but as a regulator of wnt responses, cell motility and cell-cell adhesion [23].

This fact can be of importance even for tumors of mesenchymal origin like STS.

\section{Conclusion}

In this study, we analyzed mRNA expression of an additional stem cell-associated gene, LGR5/GPR49 and its splice variant GPR49 45 , for its association with diseaseassociated and recurrence-free survival. We were able to identify GPR49 55 mRNA expression as an independent prognostic factor for STS patients. We suggest that stem-cell-associated genes play a major role in sarcoma patients' prognosis and, therefore, could be valuable targets for future therapy. Together, our results suggest a role of GPR49 55 in tumorigenesis and tumor progression of STS.

\section{List of abbreviations}

GPR49: G protein-coupled receptor; MFH: malignant fibrous histiocytoma; hMSC: human mesenchymal stem cell; HPRT: hypoxanthine

phosphoribosyltransferase; LGR5: leucine-rich repeat-containing G proteincoupled receptor; r: correlation coefficient (spearman test); RR: relative risk; STS: soft tissue sarcomas; Tcf4: T-cell transcription factor 4.

\section{Acknowledgements}

We thank our colleagues from the Department of Radiotherapy for contributing to this study and for their continuous support. S.R. and M.K. were supported by the Wilhelm-Roux-Programm of BMBF/NBL3 (FKZ: 16/18, 21/25). The work of H.T. was supported by grants of the Deutsche Krebshilfe No. 107590, the Wilhelm-Roux-Programm of BMBF/NBL3 (FKZ: 19/31) and the Deutsche Forschungsgemeinschaft GRK1591.

\section{Author details}

${ }^{1}$ Department of Radiotherapy, Martin-Luther-University Halle-Wittenberg, Halle(S), Germany. 'Department of Oral and Maxillofacial Plastic Surgery, Martin-Luther-University Halle-Wittenberg, Halle(S), Germany. ${ }^{3}$ Centre for 
Reproductive Medicine and Andrology, Martin-Luther-University HalleWittenberg, Halle(S), Germany. ${ }^{4}$ Clinic of Urology, FA University Hospital Erlangen-Nürnberg, Erlangen, Germany. ${ }^{5}$ Nikolaus-Fiebiger-Center for Molecular Medicine, FA University Erlangen-Nürnberg, Germany. ${ }^{6}$ Department of General and Visceral Surgery, Diakoniekrankenhaus Halle, Halle, Germany.

\section{Authors' contributions}

SR, HT, DV and MK designed the study, collected data, performed statistical analysis and drafted the manuscript. PW treated the patients, collected material and data and reviewed the manuscript. MB and TG made substantial contributions to the acquisition and interpretation of data. AE and JS were involved in drafting the manuscript and revising it critically. All authors read and approved the final manuscript.

\section{Competing interests}

The authors declare that they have no competing interests.

Received: 11 July 2011 Accepted: 6 October 2011

Published: 6 October 2011

\section{References}

1. Pollock RE, Karnell LH, Menck HR, Winchester DP: The National Cancer Data Base report on soft tissue sarcoma. Cancer 1996, 78:2247-2257.

2. Beck AH, West RB, van de RM: Gene expression profiling for the investigation of soft tissue sarcoma pathogenesis and the identification of diagnostic, prognostic, and predictive biomarkers. Virchows Arch 2010, 456:141-151.

3. Tolar J, Nauta AJ, Osborn MJ, Panoskaltsis MA, McElmurry RT, Bell S, Xia L, Zhou N, Riddle M, Schroeder TM, et al: Sarcoma derived from cultured mesenchymal stem cells. Stem Cells 2007, 25:371-379.

4. Choi J, Curtis SJ, Roy DM, Flesken-Nikitin A, Nikitin AY: Local Mesenchymal Stem/Progenitor Cells Are a Preferential Target for Initiation of Adult Soft Tissue Sarcomas Associated with p53 and Rb Deficiency. Am J Pathol 2010, 177:2645-2658.

5. Matushansky I, Hernando E, Socci ND, Mills JE, Matos TA, Edgar MA, Singer S, Maki RG, Cordon-Cardo C: Derivation of sarcomas from mesenchymal stem cells via inactivation of the Wnt pathway. I Clin Invest 2007, 117:3248-3257.

6. Barker N, Clevers H: Leucine-rich repeat-containing G-protein-coupled receptors as markers of adult stem cells. Gastroenterology 2010, 138:1681-1696.

7. Barker N, Clevers H: Tracking down the stem cells of the intestine: strategies to identify adult stem cells. Gastroenterology 2007, 133:1755-1760.

8. Barker N, Huch M, Kujala P, van de WM, Snippert HJ, van Es JH, Sato T, Stange $D E$, Begthel $H$, van den BM, et al: Lgr5(+ve) stem cells drive selfrenewal in the stomach and build long-lived gastric units in vitro. Cell Stem Cell 2010, 6:25-36.

9. Jaks V, Barker N, Kasper M, van Es JH, Snippert HJ, Clevers H, Toftgard R: Lgr5 marks cycling, yet long-lived, hair follicle stem cells. Nat Genet 2008, 40:1291-1299.

10. McClanahan T, Koseoglu S, Smith K, Grein J, Gustafson E, Black S, Kirschmeier P, Samatar AA: Identification of overexpression of orphan $G$ protein-coupled receptor GPR49 in human colon and ovarian primary tumors. Cancer Biol Ther 2006, 5:419-426.

11. Takahashi H, Ishii H, Nishida N, Takemasa I, Mizushima T, Ikeda M, Yokobori T, Mimori K, Yamamoto H, Sekimoto M, et al: Significance of Lgr5 (+ve) Cancer Stem Cells in the Colon and Rectum. Ann Surg Oncol 2011, 18:1166-1174.

12. Yamamoto Y, Sakamoto M, Fujii G, Tsuiji H, Kenetaka K, Asaka M, Hirohashi S: Overexpression of orphan G-protein-coupled receptor, Gpr49, in human hepatocellular carcinomas with beta-catenin mutations. Hepatology 2003, 37:528-533.

13. Tanese K, Fukuma M, Yamada T, Mori T, Yoshikawa T, Watanabe W, Ishiko A, Amagai M, Nishikawa T, Sakamoto M: G-protein-coupled receptor GPR49 is up-regulated in basal cell carcinoma and promotes cell proliferation and tumor formation. Am J Pathol 2008, 173:835-843.

14. Fan XS, Wu HY, Yu HP, Zhou Q, Zhang YF, Huang Q: Expression of Lgr5 in human colorectal carcinogenesis and its potential correlation with betacatenin. Int J Colorectal Dis 2010, 25:583-590.
15. Becker L, Huang Q, Mashimo H: Immunostaining of Lgr5, an intestinal stem cell marker, in normal and premalignant human gastrointestinal tissue. ScientificWorldJournal 2008, 8:1168-1176.

16. Dekaney CM, Gulati AS, Garrison AP, Helmrath MA, Henning SJ: Regeneration of intestinal stem/progenitor cells following doxorubicin treatment of mice. Am J Physiol Gastrointest Liver Physiol 2009, 297: G461-G470.

17. Carmon KS, Gong X, Lin Q, Thomas A, Liu Q: R-spondins function as ligands of the orphan receptors LGR4 and LGR5 to regulate Wnt//beta\}catenin signaling. Proc Natl Acad Sci USA 2011, 108:11452-11457.

18. Kappler M, Kotzsch M, Bartel F, Fussel S, Lautenschlager C, Schmidt U, Wurl P, Bache M, Schmidt H, Taubert $H$, et al: Elevated expression level of survivin protein in soft-tissue sarcomas is a strong independent predictor of survival. Clin Cancer Res 2003, 9:1098-1104.

19. Taubert H, Bartel F, Greither T, Bache M, Kappler M, Kohler T, Bohnke A, Lautenschlager C, Schmidt H, Holzhausen HJ, et al: Association of HDM2 transcript levels with age of onset and prognosis in soft tissue sarcomas. Mol Cancer Res 2008, 6:1575-1581.

20. Uchida H, Yamazaki K, Fukuma M, Yamada T, Hayashida T, Hasegawa H, Kitajima M, Kitagawa Y, Sakamoto M: Overexpression of leucine-rich repeat-containing $\mathrm{G}$ protein-coupled receptor 5 in colorectal cancer. Cancer Sci 2010, 101:1731-1737.

21. Enzinger FM, Weiss SW: Soft Tissue Tumors. 4 Aufl, St Louis Missouri, Mosby St Louis Missouri, Mosby 2001.

22. Sun $X$, Jackson L, Dey SK, Daikoku T: In pursuit of leucine-rich repeatcontaining $\mathrm{G}$ protein-coupled receptor-5 regulation and function in the uterus. Endocrinology 2009, 150:5065-5073.

23. Walker F, Zhang HH, Odorizzi A, Burgess AW: LGR5 Is a Negative Regulator of Tumourigenicity, Antagonizes Wnt Signalling and Regulates Cell Adhesion in Colorectal Cancer Cell Lines. PLoS One 2011.

\section{Pre-publication history}

The pre-publication history for this paper can be accessed here: http://www.biomedcentral.com/1471-2407/11/429/prepub

doi:10.1186/1471-2407-11-429

Cite this article as: Rot et al: A novel splice variant of the stem cell marker LGR5/GPR49 is correlated with the risk of tumor-related death in soft-tissue sarcoma patients. BMC Cancer 2011 11:429.

\section{Submit your next manuscript to BioMed Central and take full advantage of:}

- Convenient online submission

- Thorough peer review

- No space constraints or color figure charges

- Immediate publication on acceptance

- Inclusion in PubMed, CAS, Scopus and Google Scholar

- Research which is freely available for redistribution 